\title{
N 72-26555
}

NASA TECHNICAL MEMORANDUM

NASA TM X-68086

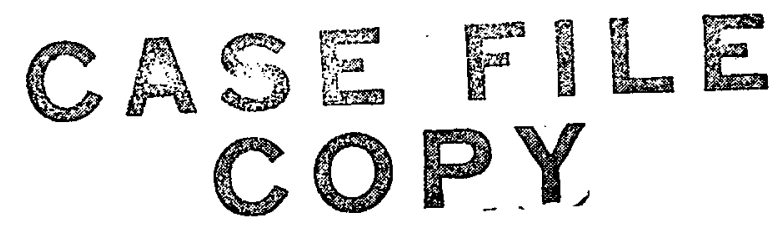

COMBINED BUOYANCY AND FLOW DIRECTION EFFECTS ON SATURATED BOILING CRITICAL_HEAT FLUX IN LIQUID NITROGEN

by S. S. Papell

Lewis Research Center

Cleveland, Ohio

TECHNICAL PAPER proposed for presentation in 1972 Cryogenic Engineering Conference

Boulder, Colorado, August 9-11, 1972 
COMBINED BUOYANCY AND FLOW DIRECTION EFFECTS ON SATURATED

BOILING CRITICAL HEAT FLUX IN LIEUID NIIROGEN

by S. S. Papell

Lewis Research Center

National Aeronautics and Space Administration

Cleveland, Ohio

\section{ABSTRACT}

Buoyancy effects on the critical heat flux and general data trends for a liquid nitrogen internal flow system were determined by comparison of upflow and downflow data under identical test conditions. The test section had a

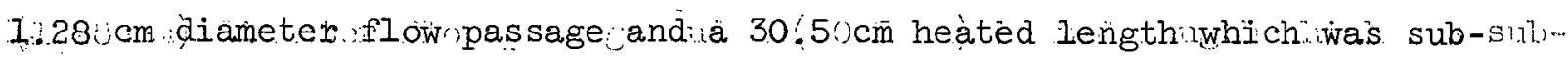
jected to uniform heat fluxes through resistance heating. Test conditions covered a range of pressures from 3:4.to 1002 atm, inletevelocities sfom 0.23 . to $t$.) $3.51 \mathrm{~m} / \mathrm{s}$, wi,th the eliquidinjtogenntemperaturesat tsaturated inileticondittionss. Data comparisons showed that the critical heat flux for downflow could be up to 36 percent lower than for upflow. A nonmonotonic relationship between the critical heat flux and velocity was determined for upflow but not for downflow.

A limiting inlet velocity of $4.12 \mathrm{~m} / \mathrm{s}$. was determined to be the minimum velocitty required to completely suppress the influence of buoyancy on the critical heat flux for this saturated inlet flow system. A correlation of this limiting fluid velocity is presented that was developed from previously published subcooled liquid nitrogen data and the saturated data of this investigation. 


\section{INTRODUCTION}

It is well known that the maximum heat flux possible for a nucleate boiling internal flow system may be markedly influenced by the various system parameters. A good analysis and literature review on this critical heat flux problem is presented by Tong, ref. 1, with emphasis on the importance of each individual parameter. In his discussion; he includes flow direction with respect to. the gravity force as a possible significant parameter but reports negatively by referring to Barnett, ref. 2. Barnett conducted tests at pressures of 37.9 atm and 136.0 atm. with a water flow system and reported no effect of flow direction on the boiling.crisis. However, Macbeth, ref. 3 and Papel1, ref. 4, have reported the existence of gravity-directed effects.

Macbeth presented an equation that correlates horizontal and vertical water flow in tube bundles for data at a pressure of $68.0 \mathrm{~atm}$. The change in orientation from vertical upward to horizontal reportedly reduced the critical heat flux significantly.

Papell, ref. 4 showed large reductions in critical heat flux for a liquid nitrogen system by a change in flow direction from upflow to downflow. The magnitude of these reductions, that ranged in values up to 86 percent; were found to be subject to fluid velocity, system pressure and subcooling for a specific flow geometry. The range of data included pressure from 3.4 to $16.3 \mathrm{~atm}$, inlet velocities from 0.15 to $3.36 \mathrm{~m} / \mathrm{s}$ and inlet subcooling from 7 to $28 \mathrm{~K}$.

The present study extends the range of data into the saturated boiling regime where it is known that the critical heat flux differs from that found. in the subcooled regime. Pokhvalov, ref. 5, for example, reported the influence 
of fluid velocity on the critical heat flux for upflow benzene boiling at saturation temperature to have different trends than that of subcooled boiling. He found the effect of velocity to be nonmonotonic so that increasing velocity could either increase or decrease the value of the critical heat flux. "The present paper, although directed primarily at the interactive effect of gravity and flow direction also examines velocity and pressure trends.

Both upflow and downflow liquid nitrogen critical heat flux data were obtained under identical test conditions with a constant heat flux, resistanceheated, $1.28-\mathrm{cm}$ diameter, $30.5-\mathrm{cm}$ long test section. The range of data included pressures from 3.4 to $10.2 \mathrm{~atm}$, inlet velocities from 0.23 to $3.51 \mathrm{~m} / \mathrm{s}$, with the inlet fluid temperature always adjusted to be at saturation conditions. The results are presented graphically.

\section{TEST EQUIPMENT}

The experimental equipment used to obtain the present saturated boiling critical heat flux data is described in ref. 4. Essentially, it consisted of a portable, stainless-steel, vacuum-jacketed flow system that operated in the blow down mode. Liquid nitrogen was pumped through the system by pressurizing a Dewar with helium gas. Connecting to the Dewar was a vacuum tank that contained an instrumented test section as part of the flow system.

The liquid nitrogen Dewar and the test section tank were both installed in an angle iron cage mounted on trunnion-type supports to permit rotation of the entire assembly. This arrangement made it posisible to change flow direction with respect to the gravity vector without any modifications to the flow system itself.

The test section, fig. (IA), was made of inconel $X$ tubing with $1.28-\mathrm{cm}$ 
flow diameter; a $0.025-\mathrm{cm}$ wall thickness; and a 30.5-cm heated length. Wall temperature measurements were made at the indicated locations with 12 copperconstantan thermocouples made of 28 gage wire. Vertical orientation of the test section mounted within the vacuum tank and flow related instrumentation is shown schematically in fig. (IB). Fluid bulk temperature measurements were made with platinum resistance thermometers.

The heat flux was generated by a 10,000 watt, 400 hertz alternator using the test section as a resistance heater. Power input to the electrodes was. measured in terms of volts and amps.

\section{EXPERTMENTAL PROCEDURE}

The procedure used to obtain the critical heat flux data was similar to the method used in ref. 4. The main difference was in adjusting the bulk fluid inlet conditions for these tests to be at saturation conditions rather than subcooled. This was accomplished by bubbling warm nitrogen gas through the liquid nitrogen with the Dewar held at a desired pressure level. When the fluid reached the saturation temperature for that particular pressure a test run was made over a range of fluid flow rates.

For a constant flow rate, the electrical power was turned on and incremently increased until. the condition of criticality was noted by monitoring the wall temperatures on a multichannel oscillograph. A temperature excursion at the downstream end of the test section signaled the time to record the data using a high speed digitizer before cutting off the power. The test procedure was then repeated over a range of flow rates and pressure levels with fluid flow through the test section vertically upward.

The direction of flow with respect to the gravity vector was then inverted 
by rotating the cage containing the Dewar and test section tank. With the test section in this orientation the tests were repeated over the same flow rates and system pressures. By careful control of the system parameters it was possible to match the upflow and downflow test conditions so that any differences in the critical heat flux data could be attributed to the influence of buoyancy on the flow system.

The data are presented graphically and some comparisons made with the subcooled inlet data of ref. 4. The range of test conditions that were matched for both upflow and downflow included system pressures from 3.4 to $10.2 \mathrm{~atm}$ over an inlet velocity range from 0.23 to $3.1 \mathrm{~m} / \mathrm{s}$. The fluid bulk inlet saturation temperature varied from 90 to $104 \mathrm{~K}$ depending on the system pressure level.

\section{DATA PRESENTATION AND DISCUSSION}

\section{Upflow Versus Downflow}

The saturated inlet critical heat flux data are plotted in fig. (2) as a function of fluid inlet velocity. Flow directions are specified by the different symbols as circles for upflow and squares for downflow. Curves drawn through the data show the general trends with comparisons made at specific system pressure levels for each plot. The velocity range over which these data are influenced by buoyancy and the magnitude of this influence can be obtained from these plots.

Fig. (2) shows that for most of the velocity range covered in this uniform heat flux study, the critical heat flux for downflow is lower than for upflow. This reduction in the critical heat flux, which can be as high as 0.36 percent, 
depends on pressure and fluid inlet velocity. The percentage difference varies over the mid-portion of the velocity range and reduces to or approaches zero at both the low and high velocity ends of the curves.

The apparent lack of buoyancy influence on the critical heat flux at both low and high velocities is consistent with the physics of the problem. At the higher velocities the momentum of the fluid is sufficient to suppress the influence of buoyancy on the flowing system. At reduced velocities, below about $0.3 \mathrm{~m} / \mathrm{s}$, a vapor choking phenomena appears as vapor generation rather than vapor removal controls the system.

\section{General Trends}

Composite graphs representing the upflow and downflow data curves of fig. (2) are presented in figure (3a) and (3b) respectively. In this manner some general trends involving pressure and velocity become apparent.

The influence of pressure on both sets of data appear to be similar. For most of the velocity range the critical heat flux is an inverse function of pressure. These results are quite interesting when coupled with the subcooled liquid nitrogen data of ref. 4 that showed an increase in critical heat flux as a result of a simultaneous increase in pressure and subcooling. From these observations it is apparent that the influence of pressure on the subcooled reference data is suppressed and points out the more significant influence of subcooling on the boiling crisis.

The composite graphs also show some general trends in the saturated inlet data curves that depend on velocity and flow direction. For the upflow case, fig. (3a), the constant pressure curves appear to maximize at an inlet velocity of about $1 \mathrm{~m} / \mathrm{s}$. At higher velocities the curves drop off at different rates 
depending on pressure and appear to be leveling off. Results similar to these have recently been reported by Pokhvalov, ref. 5, for benzene boiling at the saturation temperature.

The downflow data, fig. (3b), on the other hand, does not exhibit this maximization trend with velocity. Except for an anomaly in the 5.1 atm. data, the critical heat flux increases with velocity and appears to level of $f$ at the higher velocities.

\section{Buoyancy Versus Limiting Fluid Velocity}

The influence of buoyancy on the critical heat flux as a function of flow direction and fluid velocity has been presented graphically in figure (2). Unfortunately, due to test rig limitations, it was not possible to reach the minimum velocity, defined herein as the limiting velocity $\left(\mathrm{V}_{\text {lim }}\right)$, required to completely suppress the buoyancy influence on this saturated inlet flow system. But, since convergence of the data curves appear to be near, this information was obtained by an extrapolation technique described below.

By taking the ratio of critical heat flux upflow to downflow data and plotting $q_{C U} / q_{C D}$ as a function of inlet velocity, curves are generated that show the reduction in buoyancy influence with increased fluid velocity. The solid line on fig. (4) for the 6.8 atm saturated inlet data is quite typical. The dashed extension of this curve intersects ${ }^{q_{C U}} / q_{C D}=1$ at an inlet velocity of $4.12 \mathrm{~m} / \mathrm{s}$. Above this velocity, the critical heat flux for upflow and downflow should be the same.

The dashed lines in fig. (4) were obtained from the 6.8 atm subcooled liquid nitrogen data of ref. 4 without the need for extrapolation. Apparent differences in the curves at the same pressure level are attributed to the 
influence of inlet subcooling only. An increase in subcooling reduces the limiting velocity at which buoyancy can no longer influence the data.

All the present saturated inlet data and the subcooled data of ref. 4 were treated in the above manner. The saturated inlet curves, over a range of pressures from 3.4 to $10.2 \mathrm{~atm}$, were extrapolated out to a constant limiting velocity of $4.12 \mathrm{~m} / \mathrm{s}$. The subcooled limiting velocity data, from 3.4 to 16.3 atm, were obtained directly from ref. 4. The results are presented in table I.

Considering first only the subcooled limiting velocity data from table I, a data correlation could be obtained with the following simple equation:

$$
V_{\text {lim }}=14.7\left[(\Delta T)_{\text {sub }} x(P)\right]^{-1 / 2}
$$

with velocity in $\mathrm{m} / \mathrm{s}$ and subcooling $(\mathrm{K})$ and pressure (atm) evaluated at inlet conditions. Equation (I) is limited to a subcooling of about $5 \mathrm{~K}$ since $V_{1 i m}$ becomes infinite as $(\Delta \mathrm{T})_{\text {sub }}$ approaches zero. Using the exponential relationship between velocity, pressure and subcooling, equation (1) was modified to include the saturated inlet data of this investigation. The following equation:

$$
V_{\text {Iim }}=4.12\left[1+0.0637(\Delta \mathrm{T})_{\text {sub }} x(P)\right]^{-1 / 2}
$$

correlates both the subcooled inlet data and the saturated inlet data by satisfying the requirement that $V_{\text {lim }}$ approaches $4.12 \mathrm{~m} / \mathrm{s}$ as the subcooling approaches zero. Equation (2), presented graphically in fig. (5) can be used to estimate the velocity required to suppress the influence of buoyancy on the critical heat flux for a liquid nitrogen flow system. It should be emphasized that equation (2) is strictly empirical so that any extrapolation of these results to other test conditions or flow geometry should be made with caution. 
SUMMARY

Buoyancy effects on the critical heat flux and general data trends for a liquid nitrogen internal flow system were determined by comparison of upflow and downflow data under identical test conditions. The test section hâd... 1.28 $\mathrm{cm}$ diameter fllow passage and $30.5 \mathrm{~cm}$ heated length which'was subject to uniform heat fluxes through resistance heating. Test conditions covered a range of pressures from 3.4 to $10.2 \mathrm{~atm}$, inlet velocities from 0.23 to $3.51 \mathrm{~m} / \mathrm{s}$ with the Iiquid nitrogen at saturated inlet conditions.

The following conclusions are made for this particular, set of saturated inlet data.

(1). The critical heat flux for downflow could be up to 36 percent lower than for upflow with the percent difference depending on pressure and velocity.

(2) Fluid momentum at velocities above $4.12 \mathrm{~m} / \mathrm{s}$ and vapor choking at velocities below approximately $0.3 \mathrm{~m} / \mathrm{s}$ limit the range of velocities over which buoyancy can influence the critical heat flux.

(3) For both upflow and downflow the critical heat flux was found to be an inverse function of pressure.

(4) For upflow, the relationship between critical heat flux and velocity was found to be nonmonotonic with a maximum at an inlet velocity of about $1.0 \mathrm{~m} / \mathrm{s}$. Downflow data did not exhibit this maximization trend.

(5.) Equation (2) is presented as a data correlation of the inlet velocity. required to suppress the influence of buoyancy on the critical heat flux for both the present saturated inlet data and the subcooled data of ref. 4 . 
REFERENCES

1. Tong, L. S.: Boiling Heat Transfer and Two-Phase Flow. John Wiley \& Sons, Inc., 1965.

2. Barnett, P. G.: An Investigation into the Validity of Certain Hypotheses Implied by Various Burnout Correlations. Rep. AEEW-R-214, United Kingdom Atomic Energy Authority, June 1963.

3. Macbeth, Robert V.: Burn-Out Analysis. Part 5. Examination of Published World Data for Rod Bundles. Rep. AEEW-R-358, United Kingdom Atomic Energy Authority, June 1964.

4. Papell, S. Stephen; Simoneau, Robert J.; and Brown, Dwight D.: Buoyancy Effects on Critical Heat Flux of Forced Convective Boiling in Vertical Flow. NASA TN D-3672, 1966.

5. Pokhvalov, Yu. Ye.; Kronin, I. V.; and Yermakov, S. V.: Critical Heat Fluxes in Benzene Boiling at Saturation Temperature. Heat TransferSoviet Res., vol. 3, no. 1, Jan.-Feb. 1971, pp. 23-29. 
TABLE I

\begin{tabular}{|c|c|c|}
\hline $\begin{array}{c}\text { Pressure } \\
\mathrm{P}\end{array}$ & $\begin{array}{c}{ }^{*} \text { Subcooling } \\
(\Delta \mathrm{T})_{\text {sub }}\end{array}$ & $\begin{array}{c}\text { Limiting velocity } \\
\mathrm{V}_{\text {lim }} \\
\mathrm{m} / \mathrm{s}\end{array}$ \\
\hline 16.3 & 28 & \\
13.6 & 24 & 0.61 \\
13.6 & 14 & 0.85 \\
10.2 & 19 & 1.07 \\
10.2 & 12 & 1.07 \\
6.8 & 14 & 1.37 \\
6.8 & 9 & 1.52 \\
5.1 & 11 & 1.83 \\
3.4 & 7 & 2.14 \\
3.4 to 10.2 & 0 & 3.20 \\
& & 4.12 \\
\hline Subcoled data & from ref. 4 & \\
\hline
\end{tabular}


$\pi$
0
0
1
1
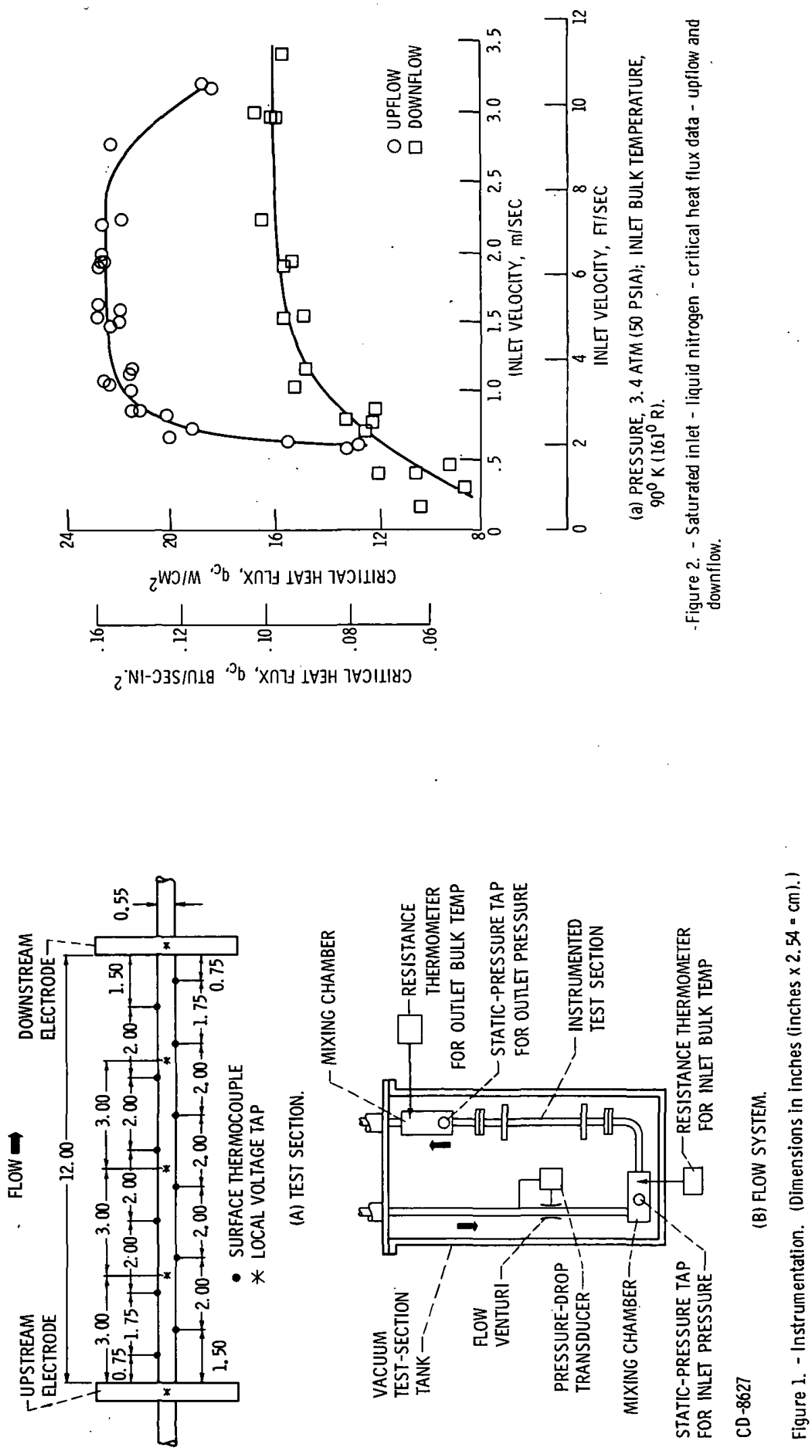


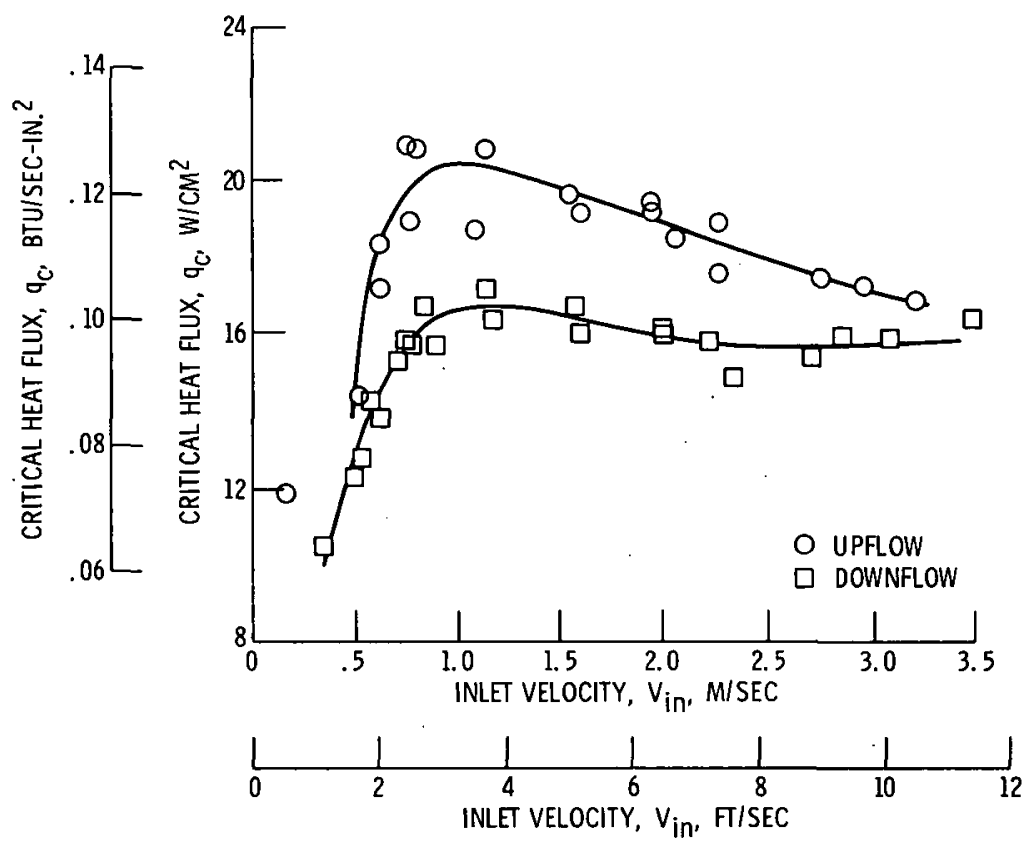

(b) PRESSURE, 5.1 ATM (75 PSIA); INLET BULK TEMPERATURE, $95^{\circ} \mathrm{K}\left(170^{\circ} \mathrm{R}\right)$.

Figure 2. - Continued.

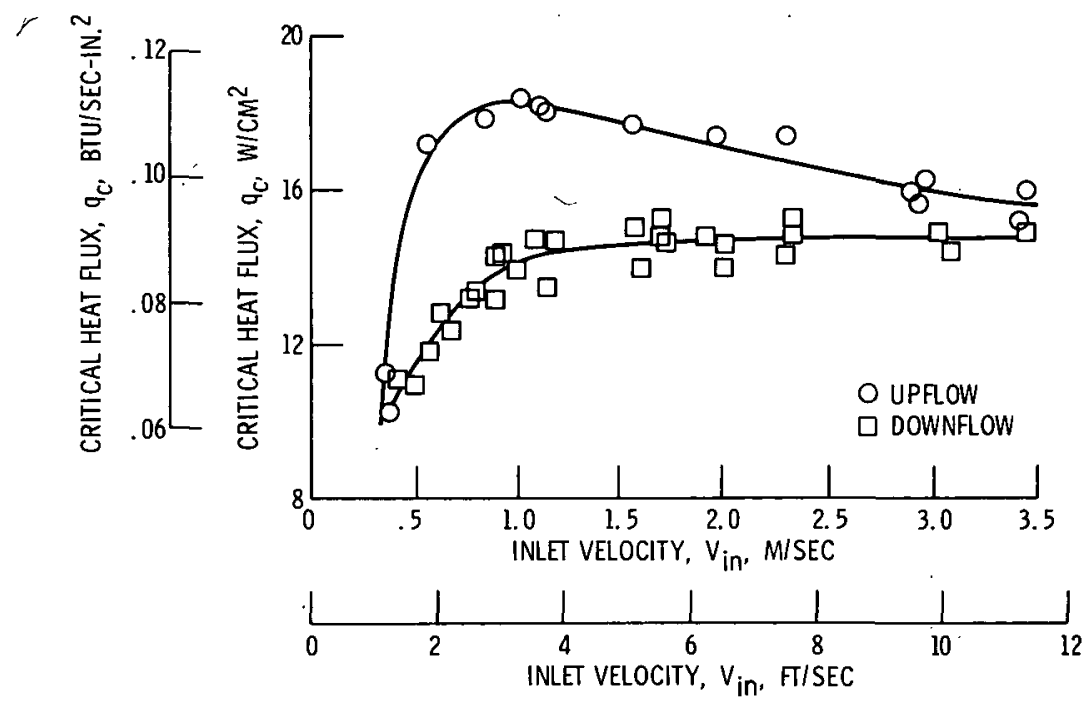

(c) PRESSURE, 6.8 ATM (100 PSIA); INLET BULK TEMPERATURE, $99^{\circ} \mathrm{K}\left(177^{\circ} \mathrm{R}\right)$.

Figure 2. - Continued. 
$\vec{a}$
$a$
0
1
1

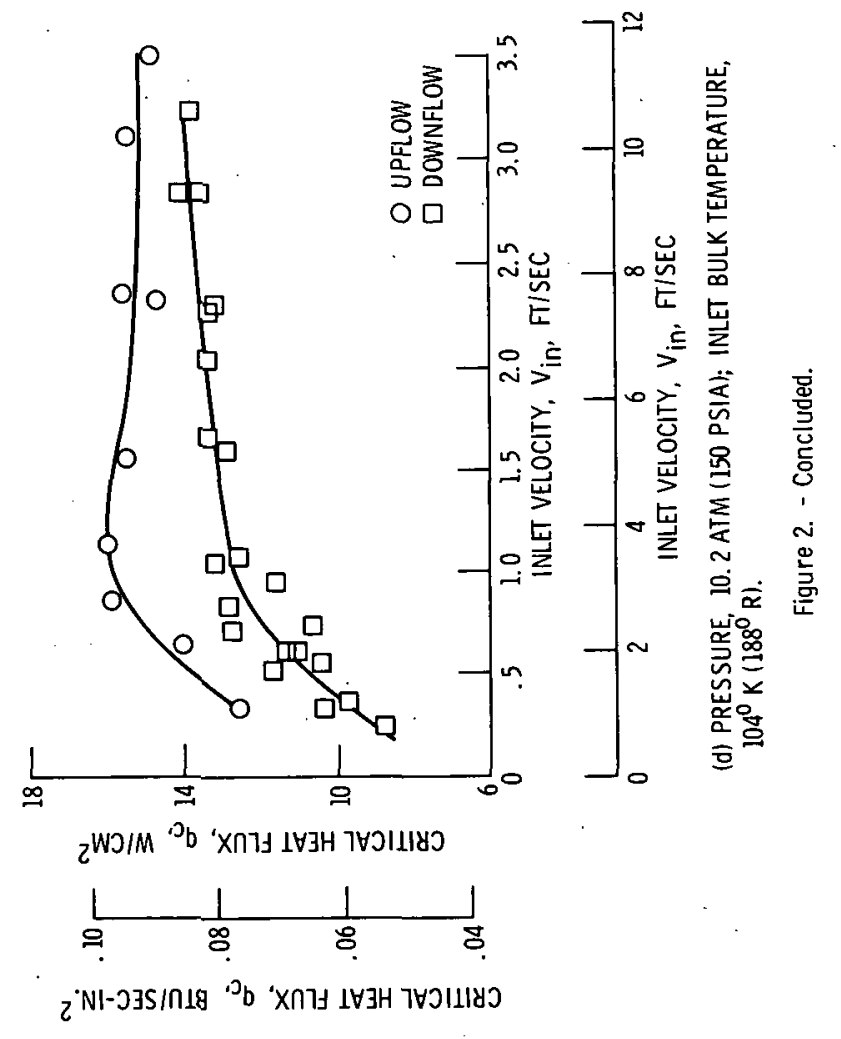

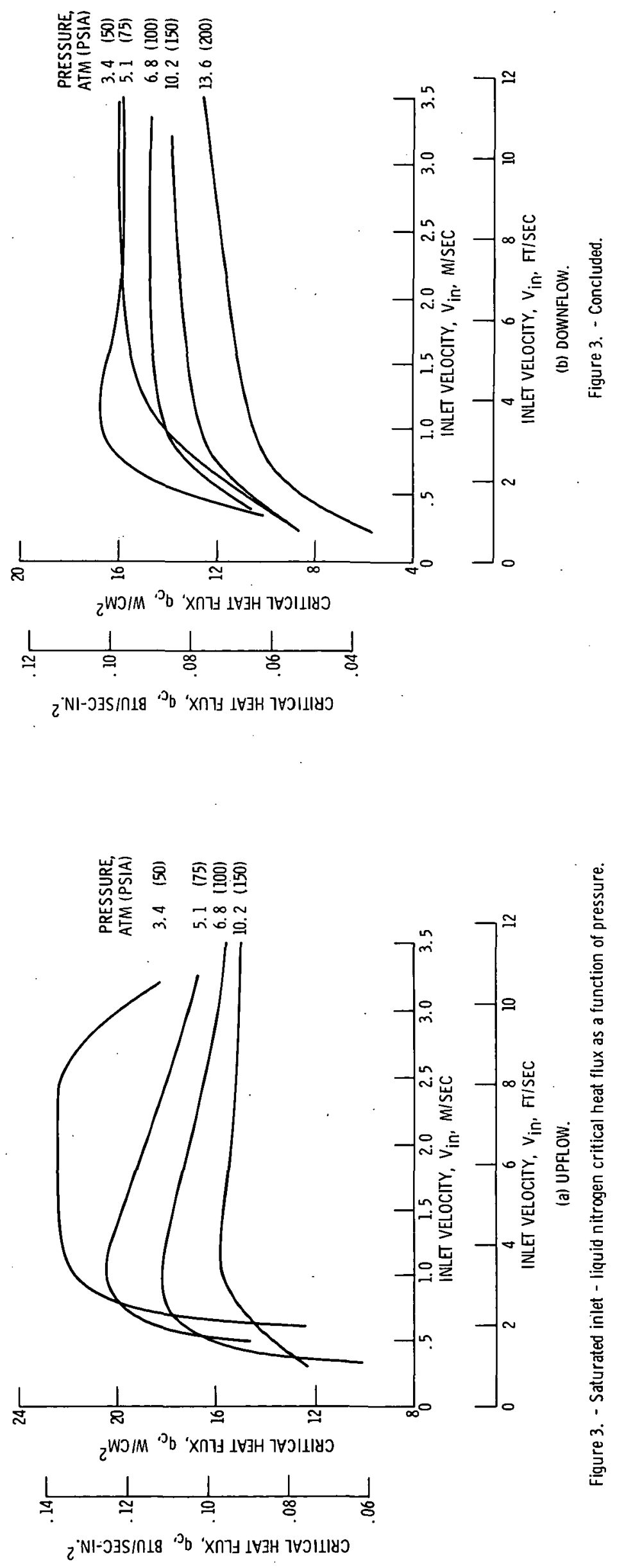



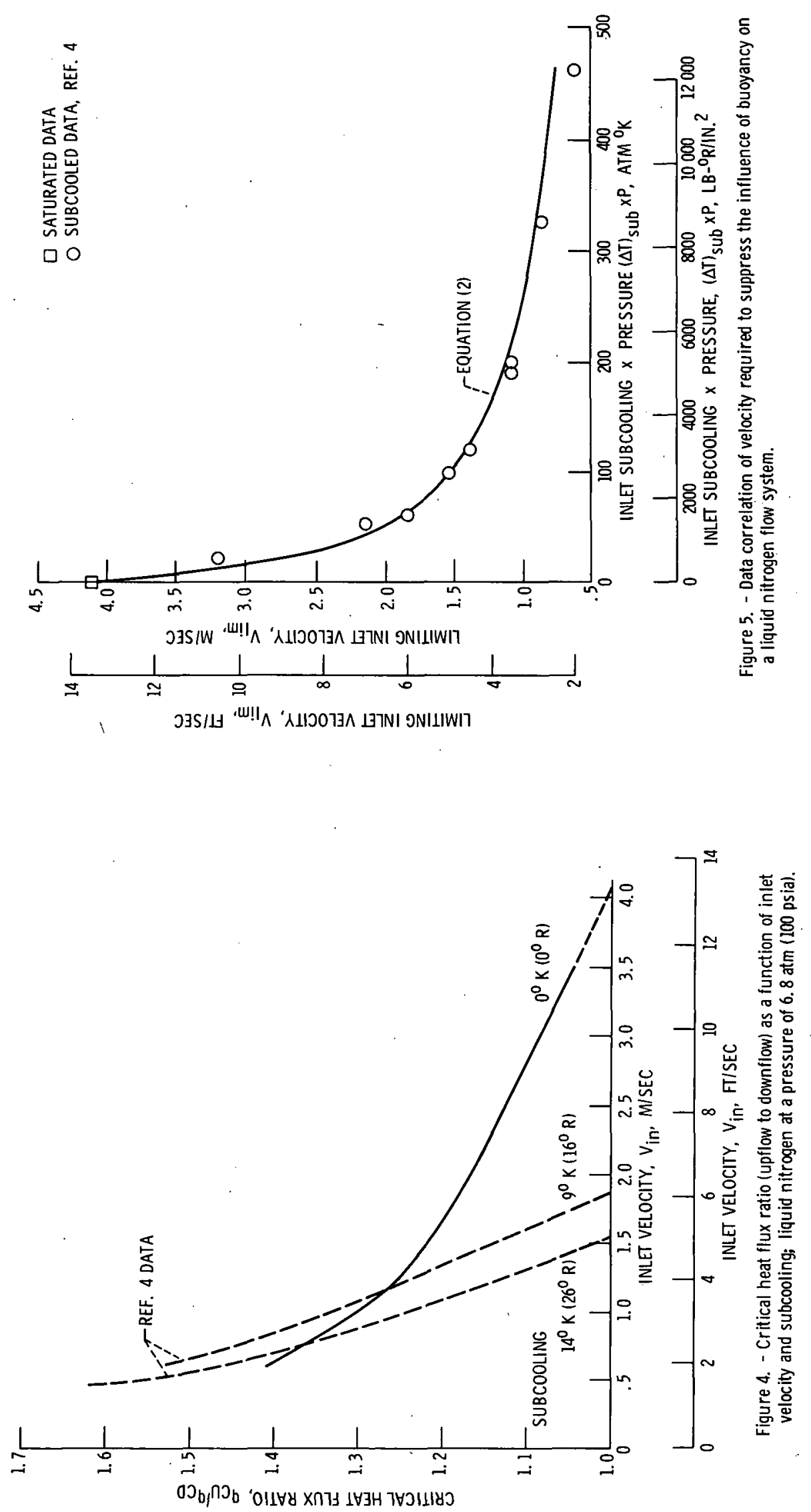

NASA-Lowis 